\title{
Argamassas eco-eficientes com incorporação simultânea de material de mudança de fase e cinzas volantes
}

\author{
Eco-efficient mortars with simultaneous \\ incorporation of phase change \\ material and fly ash
}

\footnotetext{
${ }^{1}$ Universidade do Minho, Departamento de Engenharia Civil, Campus de Azurém, 4800-058, Guimarães, Distrito de Braga, Portugal.

${ }^{2}$ Universidade de Aveiro, Campus Universitário de Santiago, 3810-193 Aveiro, Aveiro, Portugal.

${ }^{3}$ Universidade de Coimbra, Rua Luís Reis Santos - Pólo II da Universidade, 3030-788, Coimbra, Beira Litoral, Portugal. e-mail: sandracunha86@gmail.com, aguiar@civil.uminho.pt, victorf@ua.pt, tadeu@dec.uc.pt
}

\section{RESUMO}

Atualmente, a indústria da construção é um dos principais setores europeus responsáveis pelos elevados níveis de consumo de energia, extração de matérias-primas e produção de resíduos. Cada vez mais o consumo de energia proveniente de fontes renováveis e a reutilização de resíduos industriais constituem a única maneira de minimizar este problema para o meio ambiente e sociedade. A incorporação simultânea de materiais de mudança de fase (PCM) e cinzas volantes (FA) em argamassas permite aumentar a eficiência energética nos edifícios e diminuir a quantidade de extração de matérias-primas e de resíduos depositados em aterro. O desenvolvimento de argamassas com incorporação de PCM e cinzas volantes contribui para uma melhoria significativa dos parâmetros de conforto no interior de edifícios e do meio ambiente. O PCM permite regular a temperatura no interior dos edifícios utilizando como recurso apenas energia solar, diminuindo as necessidades de utilização de equipamentos de climatização. O PCM possui a capacidade de absorver e liberar energia para o meio ambiente. $O$ principal objetivo deste trabalho consistiu na caracterização física, mecânica e térmica de argamassas com incorporação de PCM e FA. Foi possível concluir que a incorporação simultânea de PCM e FA permitiu obter argamassas homogêneas e adequadas, com boas propriedades físicas e mecânicas e um comportamento térmico melhorado quando comparadas às argamassas sem incorporação e apenas com incorporação de PCM.

Palavras-chave: Material de Mudança de Fase, Cinzas Volantes, Argamassas, Cimento.

\section{ABSTRACT}

Nowadays, the construction industry is the one of the main European sector responsible for the higher levels of energy consumption, raw materials extraction and waste production. Increasingly the consumption of energy from renewable sources and reusing industrial wastes is the only way to minimize this problem for the environment and society. The simultaneous incorporation of phase change materials (PCM) and fly ash (FA) in mortars allow increase the energy efficiency in buildings and decrease the amount of the raw materials extraction and waste materials landfilled. The development of mortars with incorporation of PCM and fly ash contributes to a significant improvement of the comfort parameters inside buildings and in the environment. The PCM allow regulating the temperature inside buildings using only solar energy as a resource, decreasing the air conditioning needs. The PCM has the capability to absorb and release energy for the environment. The main purpose of this study was the physical, mechanical and thermal characterization of mortars with incorporation of PCM and FA. It was concluded that the simultaneous incorporation of PCM and FA leads to homogenous and suitable mortars, with good physical and mechanical properties and an increased thermal behavior when compared to the mortars without incorporation of PCM and only with incorporation of PCM. 
Keywords: Phase Change Material, Fly Ash, Mortars, Cement.

\section{INTRODUÇÃO}

Atualmente, assiste-se a uma enorme necessidade de proteção e melhoria do meio ambiente. Sabe-se que a indústria da construção é responsável por elevados consumos de energia e extração de matérias-primas. $\mathrm{O}$ aumento da industrialização e urbanização devido ao crescimento econômico e populacional transformou o setor de construção civil num dos setores que mais consomem recursos naturais, gerando resíduos que afetam negativamente o meio ambiente.

É de notar, que o setor de construção é responsável pelo consumo de cerca de $40 \%$ da energia produzida e pela produção de cerca de 50\% dos resíduos existentes [1-3]. Estatísticas energéticas mostram que cerca de $68 \%$ do consumo de energia nos edifícios é utilizado para climatização, enquanto que apenas cerca de $15 \%$ são usados para iluminação e utilização de eletrodomésticos, cerca de $12 \%$ para aquecimento de água e cerca de $4 \%$ para cozinhar [3].

Apesar das medidas de eficiência energética desenvolvidas na Europa, o consumo global de energia nos edifícios continua a aumentar, em particular relacionado com os equipamentos de ar condicionado [3]. Assim, a diminuição das necessidades de climatização de um edifício representam uma importante oportunidade de economia de energia. Por outro lado, atualmente, a geração de resíduos industriais aumentou em todo o mundo, tornando-se cada vez mais importante utilizar os resíduos industriais para reduzir o seu deposito em aterro.

É sabido que o material de construção mais utilizado em todo o mundo é o betão. Estima-se que a produção anual de cimento seja de aproximadamente 1,6 bilhões de toneladas, o que corresponde a cerca de $7 \%$ da carga global de dióxido de carbono na atmosfera [4]. Por outro lado, as cinzas volantes têm vindo a ser utilizadas na indústria da construção. Este subproduto resulta da queima de carvão durante a produção de energia nas centrais termoelétricas. Vários estudos mostram que a utilização de cinzas volantes, em substituição parcial do cimento Portland na produção de betão, contribui para a redução das emissões de $\mathrm{CO}_{2}$ para a atmosfera [4]. Assim, torna-se importante minimizar o consumo elevado de energia proveniente de fontes não renováveis através da utilização de fontes de energia renováveis, assim como o reaproveitamento e reutilização de resíduos industriais com vista à diminuição da extração de materiais naturais.

Os materiais de mudança de fase (PCM) são materiais funcionais, que permitem regular a temperatura no interior dos edifícios utilizando apenas energia solar como recurso, diminuindo as necessidades de climatização com base numa fonte de energia renovável. Por sua vez, a produção de cinzas volantes aumentou em todo o mundo, e o seu aterro tornou-se um grave problema ambiental. Assim, a incorporação simultânea de PCM e cinzas volantes em argamassas à base de cimento aparece como uma possível solução, na tentativa de resolver, ou pelo menos minimizar, o consumo energético e eliminar parte dos resíduos colocados em aterro, contribuindo para uma melhoria significativa dos parâmetros de conforto no interior de edifícios e uma melhoria para o ambiente, quer na diminuição da extração de matéria-prima e consumos energéticos associados, e diminuição da valorização de resíduos industriais.

O PCM é ativado pela temperatura ambiente, sendo que quando a temperatura aumenta, o PCM transita de fase, do estado sólido para o estado líquido, absorvendo e armazenando energia do ambiente. Por sua vez, o ciclo completa-se quando a temperatura ambiente diminui. Nesta situação, o PCM libeta a energia armazenada anteriormente para o meio ambiente, transitando novamente de estado, neste caso, do estado líquido para o estado sólido.

A utilização simultânea de PCM e cinzas volantes em argamassas de cimento para revestimento no interior dos edificios permite obter benefícios sociais, econômicos e ambientais. Os benefícios sociais estão diretamente ligados à diminuição das flutuações de temperatura no interior dos edifícios, aumentando o conforto térmico no interior dos mesmos. Os benefícios ambientais encontram-se relacionados com a diminuição da extração de combustíveis fósseis, causada pela diminuição da utilização de equipamentos de climatização. Por outro lado, o uso de cinzas volantes como substituição parcial de cimento possui inúmeros benefícios, incluindo a redução da quantidade de resíduos depositados em aterros, das emissões de gases com efeito de estufa e o consumo de energia [5]. Os benefícios econômicos encontram-se relacionados com a redução no consumo de energia, o atraso no consumo de energia e no uso de materiais mais baratos, como resíduos industriais.

Ao longo dos últimos anos, muitos estudos têm vindo a ser publicados relativamente aos materiais de mudança de fase. As placas de gesso com incorporação de microcápsulas de PCM foram um dos principais materiais de construção estudados, devido ao seu baixo custo e facilidade de aplicação [6-8]. A incorporação 
de microcápsulas de PCM em betão e argamassas também foi alvo de investigação [9-12]. Existem também outros estudos com incorporação de PCM em materiais de construção, como por exemplo painéis de PVC, blocos e tijolos [13-15]. Mais recentemente, diferentes trabalhos foram publicados no que diz respeito à incorporação de microcápsulas de PCM em argamassas. Cunha et al. [11] investigaram argamassas aditivadas com PCM baseadas em diferentes ligantes, concluindo que a incorporação de PCM provoca um aumento na relação água/ligante e consequente uma diminuição nas propriedades mecânicas. Outro estudo foi publicado sobre a influência da incorporação de diferentes materiais de mudança de fase, provando-se que a utilização de diferentes tipos de microcápsulas de PCM afeta as propriedades físicas e mecânicas das argamassas [12].

Embora tenham sido vários os estudos realizados com PCM, a incorporação simultânea de PCM e cinzas volantes ainda continua a ser uma lacuna no conhecimento. Assim, o principal objetivo deste estudo consistiu no desenvolvimento e caracterização de argamassas de cimento com adição simultânea de microcápsulas de PCM e cinzas volantes. Para tal, foram desenvolvidas 12 composições distintas, com diferentes teores de PCM e cinzas volantes, avaliando as suas propriedades físicas, mecânicas e térmicas.

\section{MATERIAIS, COMPOSIÇÕES E PROCEDIMENTOS DE ENSAIO}

\subsection{Materiais}

A seleção dos materiais levou em consideração trabalhos anteriores [11, 13-16]. As argamassas desenvolvidas foram baseadas em diferentes materiais: cimento, cinzas volantes, PCM, areia, superplastificante e fibras.

O cimento utilizado é do tipo II 32.5 e apresenta uma densidade de $3030 \mathrm{~kg} / \mathrm{m}^{3}$.

Tendo como objetivo o conhecimento das microcápsulas de PCM foram efetuados vários ensaios para a sua caracterização. As microcápsulas são constituídas por uma parede em melamina-formaldeído, com temperatura de transição de $24^{\circ} \mathrm{C}$ no ciclo de aquecimento e de $21^{\circ} \mathrm{C}$ no ciclo de arrefecimento (Figura 1), assim como uma entalpia de $147.9 \mathrm{~kJ} / \mathrm{kg}$. Através de ensaios realizados com recurso ao microscópio eletrónico de varredura de alta resolução, foi possível observar, que o polímero presente nas microcápsulas de PCM apresenta uma textura regular (Figura 2). Com o objetivo de obter dados mais precisos relacionados com as suas dimensões, foram realizados ensaios de granulometria, com recurso a um granulómetro laser. Foi possível observar que as microcápsulas de PCM possuem dimensões entre 5.8-339 $\mu \mathrm{m}$, apresentando uma dimensão média de $43.91 \mu \mathrm{m}$ (Figura 3).

A areia utilizada é constituída essencialmente por partículas com dimensões entre $0.125 \mathrm{~mm}$ e $0.5 \mathrm{~mm}$, com uma dimensão média de $439,9 \mu \mathrm{m}$ e uma massa específica real de $2600 \mathrm{~kg} / \mathrm{m}^{3}$. O superplastificante utilizado é baseado em poliacrilato, com densidade de $1050 \mathrm{~kg} / \mathrm{m}^{3}$, comercializa-do pela BASF e com denominação comercial de Glenium Sky. As fibras utilizadas são fibras sintéticas de poliamida, com um comprimento de $6 \mathrm{~mm}$ e densidade de $1380 \mathrm{~kg} / \mathrm{m}^{3}$. Por último, as cinzas volantes utilizadas foram produzidas na central termoelectrica do Pego, em Portugal, com uma densidade de $2420 \mathrm{~kg} / \mathrm{m}^{3}$.

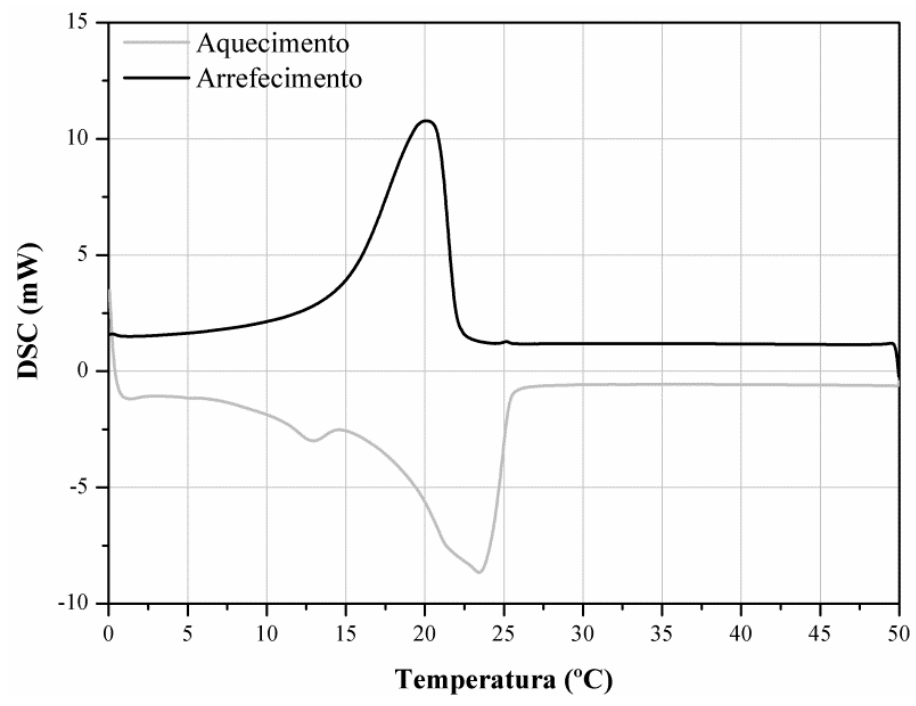

Figura 1: Termograma das microcápsulas de PCM. 


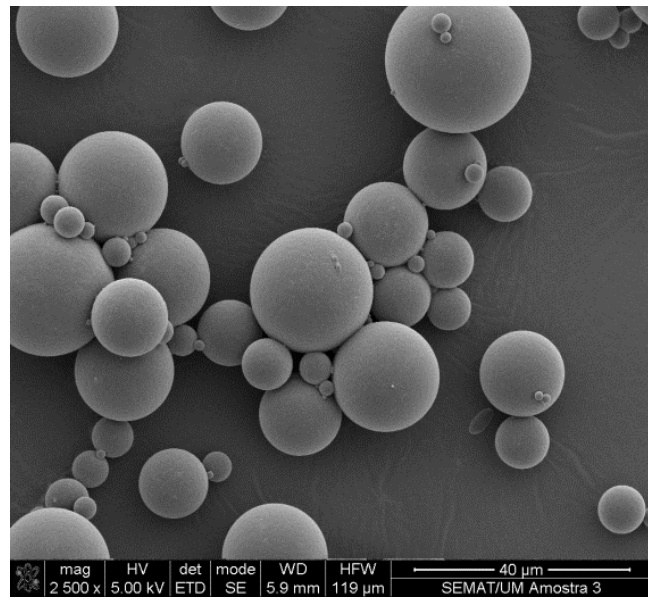

Figura 2: Observação das microcápsulas de PCM.

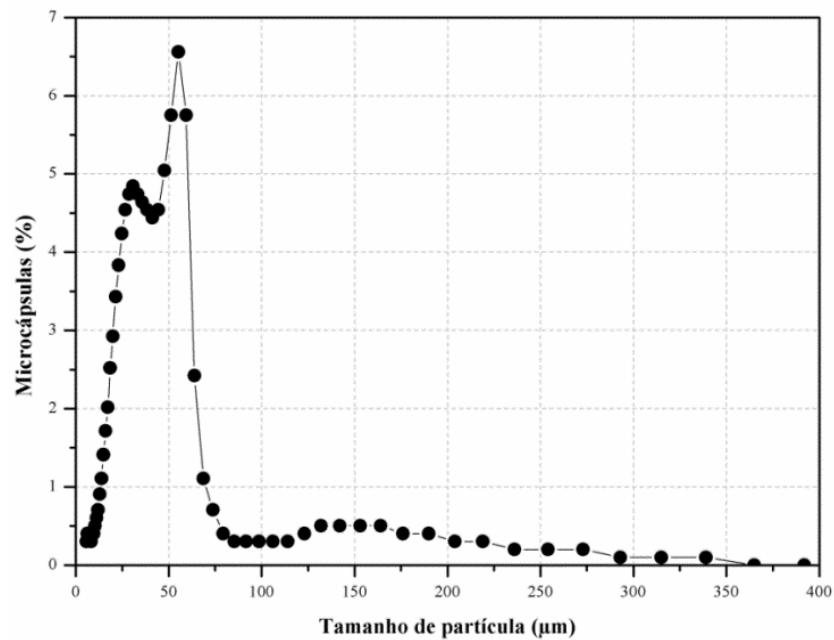

Figura 3: Granulometria das microcápsulas de PCM.

O processo de mistura e fabrico dos provetes para a determinação das várias propriedades das argamassas, foi realizado de acordo normas europeias especificas.

Após o fabrico, todos os provetes foram conservados durante 7 dias em sacos de polietileno, sendo posteriormente colocados em laboratório à temperatura ambiente (cerca de $22^{\circ} \mathrm{C}$ ) durante 21 dias e posteriormente ensaiados aos 28 dias de idade.

\subsection{Composições}

$\mathrm{O}$ estudo da incorporação simultânea de PCM e cinzas volantes em argamassas à base de cimento foi desenvolvido com base em 12 formulações distintas (Tabela 1). Foram desenvolvidas argamassas de referência, ou seja sem incorporação de PCM e cinzas volantes, argamassas com incorporação de cinzas volantes em três teores distintos $(20 \%, 40 \%$ e $60 \%$ em substituição da massa de cimento) e ainda argamassas aditivadas com cinzas volantes e material de mudança de fase ( $40 \%$ da massa de agregado). Com o objetivo de evitar elevados níveis de retração foram ainda incorporadas às argamassas com PCM e cinzas volantes, fibras de poliamida ( $1 \%$ da massa de cimento).

\subsection{Procedimentos de ensaio}

A caracterização das argamassas foi realizada com base no estudo do seu comportamento físico, mecânico e térmico.

No que diz respeito à caracterização física foram realizados ensaios de trabalhabilidade, absorção de água por capilaridade, absorção de água por imersão e observações microscópicas.

A determinação da trabalhabilidade das argamassas foi efectuada de acordo com o método da mesa de 
espalhamento, especificado na norma EN 1015-3 [17]. Os resultados foram considerados válidos somente quando o valor resultante foi de $205 \pm 5 \mathrm{~mm}$.

Tabela 1: Formulação das argamassas $\left(\mathrm{kg} / \mathrm{m}^{3}\right)$.

\begin{tabular}{|c|c|c|c|c|c|c|c|}
\hline COMPOSIÇÃO & CIMENTO & CINZAS VOLANTES & AREIA & PCM & SUPERPLASTIFICANTE & FIBRAS & ÁGUA \\
\hline C100CV0PCM0 & 500 & 0 & 1418.8 & 0 & 15 & 0 & 275 \\
\hline C80CV20PCM0 & 400 & 100 & 1396.8 & 0 & 15 & 0 & 275 \\
\hline C60CV40PCM0 & 300 & 200 & 1401.2 & 0 & 15 & 0 & 265 \\
\hline C40CV60PCM0 & 200 & 300 & 1366.6 & 0 & 15 & 0 & 270 \\
\hline C100CV0PCM40 & 500 & 0 & 644.3 & 257.7 & 15 & 0 & 280 \\
\hline C80CV20PCM40 & 400 & 100 & 646.2 & 258.5 & 15 & 0 & 270 \\
\hline C60CV40PCM40 & 300 & 200 & 630.3 & 252.1 & 15 & 0 & 275 \\
\hline C40CV60PCM40 & 200 & 300 & 611.5 & 244.6 & 15 & 0 & 282.5 \\
\hline C100CV0PCM40F & 500 & 0 & 622.2 & 248.88 & 15 & 5 & 295 \\
\hline C80CV20PCM40F & 400 & 100 & 618.0 & 247.2 & 15 & 4.0 & 290 \\
\hline C60CV40PCM40F & 300 & 200 & 602.2 & 240.9 & 15 & 3.0 & 295 \\
\hline C40CV60PCM40F & 200 & 300 & 586.3 & 234.5 & 15 & 2.0 & 300 \\
\hline
\end{tabular}

O ensaio para determinação da absorção de água por capilaridade foi efetuado com base na especificação EN 1015-18 [18]. Os elementos de ensaio foram obtidos por corte, atraves dos ensaios de flexão de 3 provetes prismáticos, resultando assim em 6 elementos de ensaio. Em todos os provetes optou-se por colocar em contacto com a água a face resultante das operações de corte de acordo com o ensaio de flexão. Garantindo-se desta forma que a face em contacto com a água possuía os canais capilares realmente presentes na argamassa em estudo, eliminando-se desta forma o contacto da água com uma face mais rica em finos e consequentemente com menos vazos capilares. A quantificação da água absorvida foi realizada através da realização de sucessivas pesagens dos provetes. Estas pesagens foram feitas de acordo com um plano de pesagens previamente estabelecido, com início no primeiro contato dos provetes com a água. Com o objetivo de avaliar a evolução de absorção de água até à sua estabilização, foram realizadas medições periódicas durante 9 dias. As pesagens foram sempre efetuadas depois de removida a água superficial.

A determinação da absorção de água por imersão foi efetuada com base na especificação do LNEC E 394 [19]. Inicialmente os provetes foram secos em estufa até atingirem a massa contante. Posteriormente foram saturados num recipiente com água de consumo a uma temperatura de $20 \pm 3^{\circ} \mathrm{C}$, ate atingirem novamente a massa constante, ou seja uma variação de massa inferior a $0.1 \%$ em medições sucessivas intervaladas de 24 horas. Por último foi determinada a sua massa hidrostática após a saturação.

A observação da microestrutura das argamassas foi realizada com recurso a um microscópio eletrónico de varrimento. Para cada composição, foram preparadas dois elementos de ensaio cilíndricos com diâmetro e altura de aproximadamente $1 \mathrm{~cm}$.

O comportamento mecânico foi avaliado segundo a determinação da resistência à flexão e compressão e da aderência.

A preparação dos provetes e a realização dos ensaios decorreu em conformidade com a norma europeia EN 1015-11 [20]. Após a sua preparação, todos os elementos de ensaio foram armazenados 7 dias em sacos de polietileno e posteriormente colocados em laboratório à temperatura ambiente $\left(22^{\circ} \mathrm{C}\right)$ durante 21 dias. Os ensaios de determinação das resistências à flexão e compressão foram realizados com controlo de força a uma velocidade de $50 \mathrm{~N} / \mathrm{s}$ e $150 \mathrm{~N} / \mathrm{s}$, respetivamente.

Relativamente à determinação da aderência, a mistura e preparação dos provetes efectuou-se de acordo com a norma europeia EN 1015-12 [21]. Para cada composição estudada foi preparada uma amostra aplicada num subtrato tradicional da industria da construção (tijolo). Após a sua preparação, todos os elementos de ensaio foram armazenados durante 7 dias em sacos de polietileno e posteriormente colocados em laboratório à temperatura ambiente $\left(22^{\circ} \mathrm{C}\right)$ durante 21 dias. Posteriormente, com recurso a uma caroteadora foram preparados 5 provetes de base circular com um diâmetro de $50 \mathrm{~mm}$.

Por último, o comportamento térmico foi testado com recurso a uma câmara climática, programada com uma lei de temperatura representativa da estação do ano a ser analisada. Para cada composição, desen- 
volveu-se uma célula de ensaio em pequena escala feita com um material isolante (poliestireno extrudido) com $3 \mathrm{~cm}$ de espessura. As células possuem uma dimensão de 200x200x200 mm e foram revestidas no seu interior com uma camada de argamassa de $1 \mathrm{~cm}$ de espessura. Foram ainda colocados termopares no interior e exterior das células para uma rigorosa medição das variações de temperatura. A realização destes ensaios permitiu obter o desempenho térmico das várias argamassas desenvolvidas nas diferentes estações do ano. Os dados meteorológicos utilizados neste ensaio foram obtidos através de uma estação meteorológica instalada no campus de Azurém da Universidade do Minho em Guimarães. As leis de temperatura utilizadas para cada estação do ano encontram-se na Figura 4. A simulação de cada estação foi realizada com base em 3 ciclos de ensaio, cada um com uma duração de 24 horas. A gama de temperaturas utilizadas para a simulação da estação de inverno oscilou entre os $5^{\circ} \mathrm{C}$ e $22^{\circ} \mathrm{C}$. A simulação da estação de verão foi realizada com uma lei de temperatura entre os $11^{\circ} \mathrm{C}$ e $44^{\circ} \mathrm{C}$. Para a simulação da estação de primavera foram utilizadas temperaturas entre os $12^{\circ} \mathrm{C}$ e $29^{\circ} \mathrm{C}$. Por último, a simulação da estação de outono foi avaliada com base numa gama de temperaturas entre os $17^{\circ} \mathrm{C}$ e $34^{\circ} \mathrm{C}$.
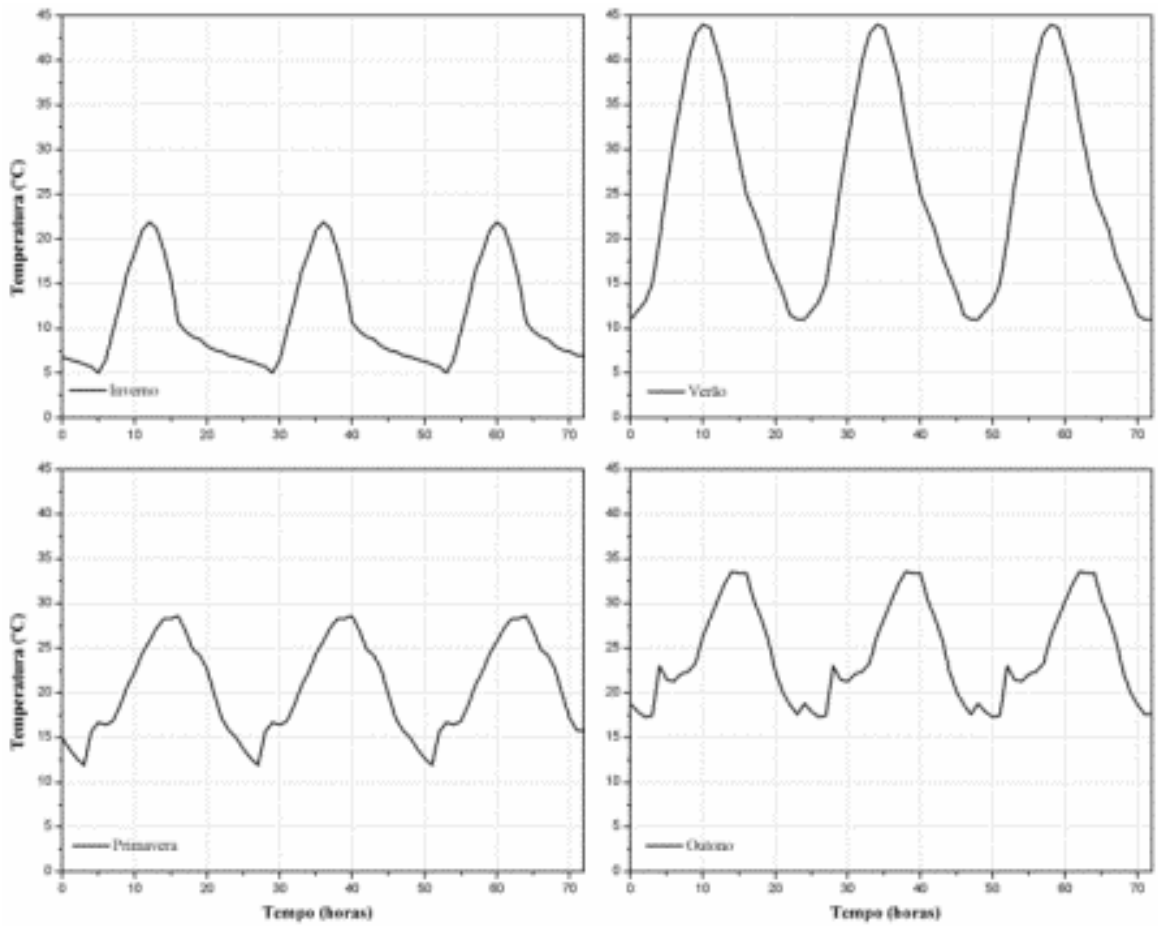

Figura 4: Leis de temperatura das diferentes estações do ano.

\section{RESULTADOS E DISCUSSÃO}

\subsection{Trabalhabilidade}

A facilidade de aplicação de uma argamassa no estado fresco encontra-se diretamente relacionada com a sua trabalhabilidade.

A Figura 5 revela que a incorporação de cinzas volantes originou uma ligeira modificação na quantidade de água adicionada para as argamassas à base de cimento. Verificou-se ainda que a incorporação de cinzas volantes originou um aumento da razão água/cimento devido à diminuição do teor de cimento nas argamassas.

As argamassas de cimento com incorporação simultânea de PCM e fibras mostraram uma ligeira diminuição na quantidade de água para uma incorporação de $20 \%$ de cinzas volantes. Este comportamento pode ser justificado pela forma mais esférica das partículas de cinzas volantes quando comparada com os outros constituintes das argamassas [22]. No entanto, a adição de maiores quantidades de cinzas volantes levou a um aumento da quantidade de água.

Relativamente às argamassas sem incorporação de PCM, foi possível verificar que a incorporação de $20 \%$ de cinzas volantes não causou qualquer alteração na quantidade de água. No entanto, verificou-se uma ligeira diminuição na quantidade de água para a incorporação de $40 \%$ de cinzas volantes e um ligeiro aumen- 
to na quantidade de água para uma adição de $60 \%$ de cinzas volantes.

Para uma incorporação de $20 \%$ de cinzas volantes, foi possível observar uma tendência para a diminuição da quantidade de água adicionada às argamassas. Este comportamento pode ser justificado pelo facto das partículas de cinzas volantes possuírem uma forma mais próxima da esférica, comparativamente com as partículas de cimento. Por outro lado, o aumento do teor de cinzas volantes permitiu verificar uma tendência para o aumento da quantidade de água, devido à presença de um teor mais elevado de partículas de pequenas dimensões.
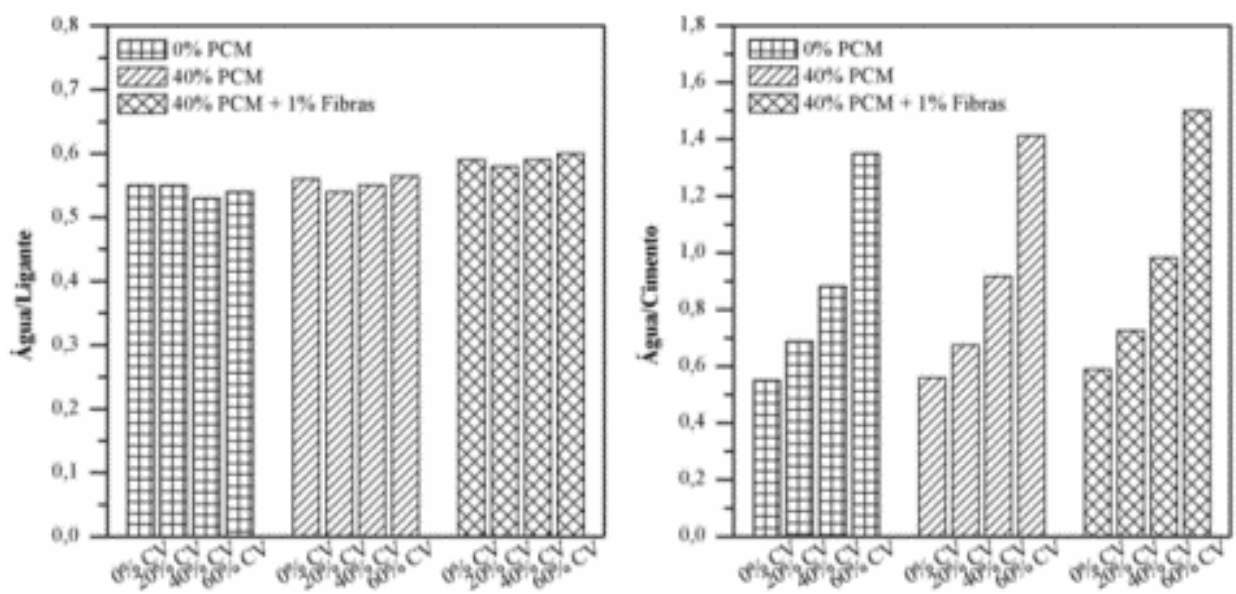

Figura 5: Trabalhabilidade das argamassas com incorporação de cinzas volantes e microcápsulas de PCM: Relação águaligante e relação água-cimento, da esquerda para a direita.

Foi também possível observar que as argamassas com a incorporação de PCM e com incorporação de PCM e fibras revelaram uma maior necessidade de água, comparativamente com as argamassas sem adição de PCM. Esta situação pode ser justificada pelo efeito de aglomeração devido à incorporação de fibras.

\subsection{Microestrutura}

A Figura 6 apresenta a microestrutura das argamassas com incorporação de PCM, fibras e cinzas volantes. Estas observações revelam uma boa interação entre os diferentes materiais devido à ausência de fissuras na interface de ligação dos mesmos. No que confere à interação entre as cinzas volantes e o cimento pode observar-se uma excelente ligação, uma vez que estes formam uma pasta ligante homogénea. Verificou-se ainda uma boa distribuição das partículas de PCM o que permite concluir que o processo de fabrico se encontra adequado. Contudo, nas argamassas com incorporação de cinzas volantes foi possível observar a presença de uma menor quantidade de produtos resultantes das reações de hidratação, quando comparados com as argamassas sem incorporação de cinzas volantes.

Com o objetivo de avaliar a influência das cinzas volantes no tamanho e distribuição dos poros das argamassas, foram realizadas outras observações microscópicas (Figura 7). Foi possível observar que a incorporação de cinzas volantes originou uma quantidade superior de poros com dimensões mais baixas, comparativamente com a argamassa de referência ( $0 \%$ cinzas volantes). Este comportamento encontra-se relacionado com o atraso das reações de hidratação e pelo aumento da relação água/cimento. Chindaprasirt et al. [23] revelaram que a utilização de cinzas volantes como material pozolânico tende a aumentar a durabilidade de argamassas devido ao refinamento dos poros e à redução do hidróxido de cálcio na matriz de pasta de cimento.

\subsection{Absorção de água por capilaridade}

A Figura 8 apresenta o coeficiente de absorção de água por capilaridade das argamassas com incorporação simultânea de microcápsulas de PCM e cinzas volantes. Tendo sido possível observar uma ligeira diminuição no coeficiente de absorção por capilaridade com a incorporação de $20 \%$ de cinzas volantes nas argamassas. Esta situação pode ser explicada pela pequena diminuição da quantidade de água presente nas argamassas. Por outro lado, a incorporação de uma maior quantidade de cinzas volantes $(40 \%$ e $60 \%)$ originou um aumento do coeficiente de absorção por capilaridade, devido ao aumento da razão água/ligante destas argamassas. Sendo que, a incorporação de $40 \%$ de cinzas volantes provocou um aumento no coeficiente de absorção 
capilar superior a 69\%, com a exceção de argamassas sem incorporação de PCM nas quais não se observou qualquer alteração significativa. A incorporação de $60 \%$ de cinzas volantes levou a um aumento no coeficiente de absorção de água por capilaridade superior a 32\%, com exceção das argamassas com incorporação de fibras e PCM nas quais não se verificou um aumento significativo. O aumento do coeficiente de absorção capilar com a incorporação de cinzas volantes encontra-se relacionado com o aumento da razão água/ligante e também pelo aumento dos poros de pequenas dimensões, tal como pode ser observado na Figura 7.
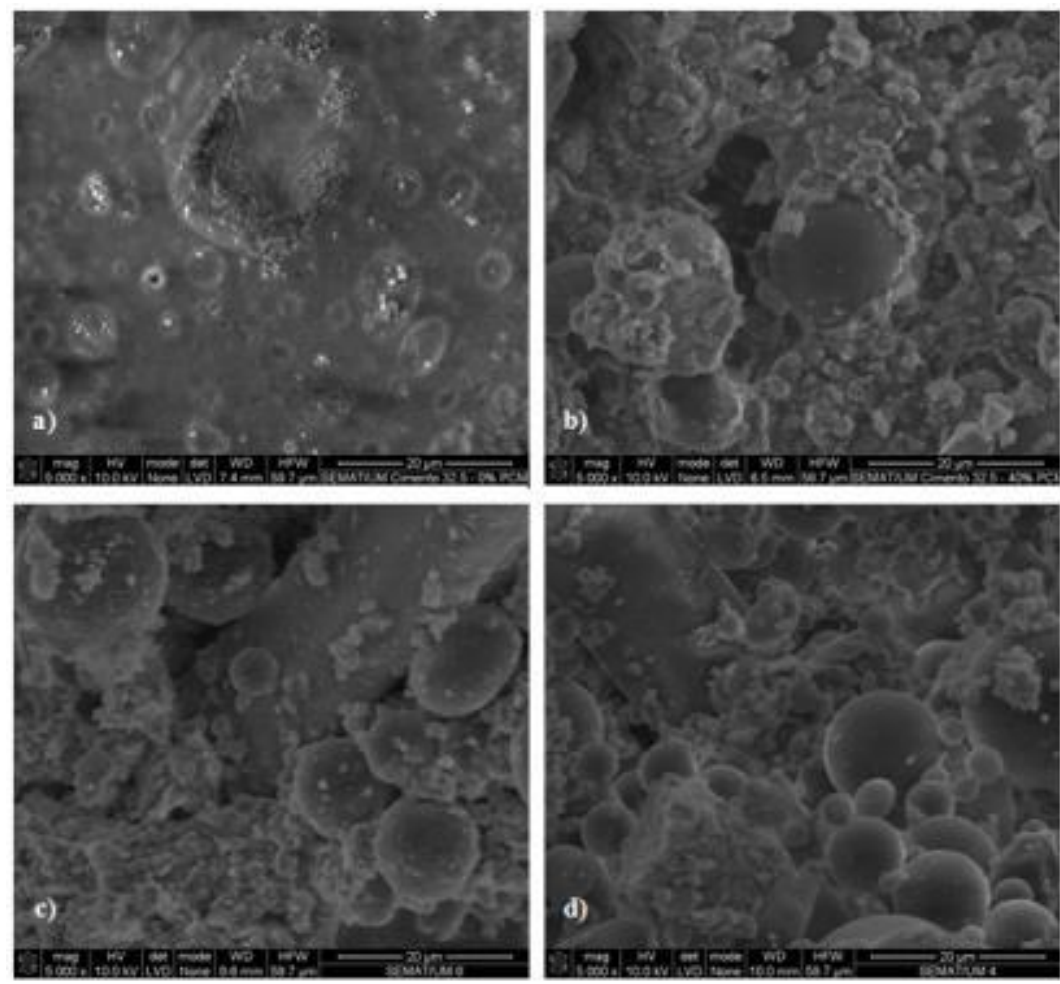

Figura 6: Microestrutura de argamassas de cimento, ampliação de 5000x: a) C100CV0PCM0; b) C100CV0PCM40; c) C100CV0PCM40F; d) C40CV60PCM40F.

A Figura 9 apresenta a absorção de água das argamassas durante 14 dias, ou seja até à estabilização da massa dos elementos de ensaio. Foi possível observar que as argamassas com incorporação de $60 \%$ de cinzas volantes apresentaram uma maior absorção de água, o que se encontra relacionado com a presença de uma maior quantidade de microporos na sua matriz (Figura 7). Por outo lado, as argamassas com incorporação de $20 \%$ de cinzas volantes apresentam menores níveis de absorção de água por capilaridade.

As argamassas com incorporação de PCM e fibras apresentaram maiores níveis de absorção de água, devido ao maior teor de água presente nas mesmas.

\subsection{Absorção de água por imersão}

De acordo com a Figura 10, foi possível observar que a incorporação de cinzas volantes não causou alterações significativas na absorção de água por imersão. No entanto, foi possível identificar que a incorporação de $40 \%$ e $60 \%$ de cinzas volantes causou um ligeiro aumento na absorção de água, devido à presença de uma maior razão água/ligante e devido à lenta reatividade das cinzas volantes. Foi também possível verificar que as argamassas de cimento com a incorporação de PCM, e com incorporação de PCM e fibras revelam maiores níveis de absorção de água quando comparadas com as argamassas sem incorporação de PCM. Este comportamento pode ser justificado pela presença de um maior teor de água nas argamassas, devido à reduzida dimensão das microcápsulas de PCM. 

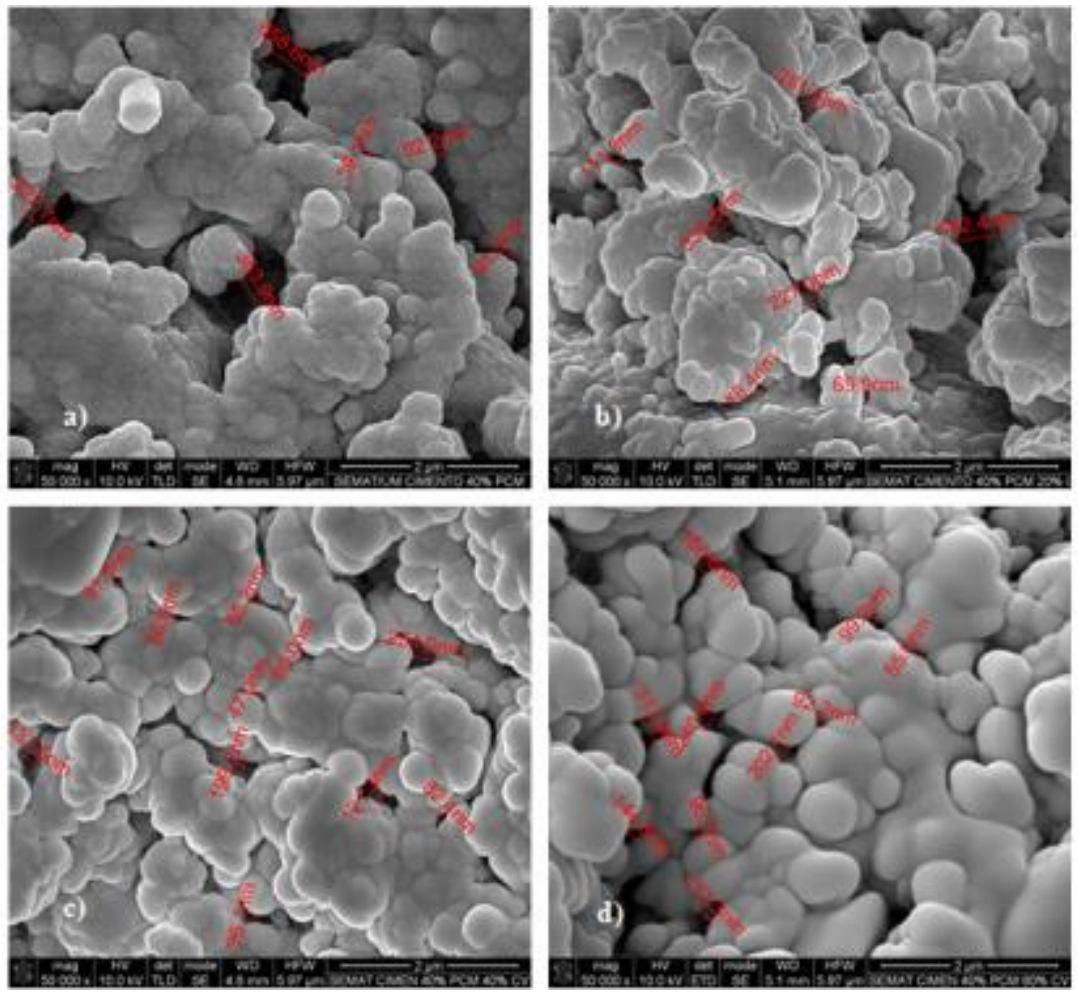

Figura 7: Microestrutura de argamassas de cimento, ampliação de 50000x: a) C100CV0PCM40F; b) C80CV20PCM40F; c) $\mathrm{C} 60 \mathrm{CV} 40 \mathrm{PCM} 40 \mathrm{~F} ; \mathrm{d}) \mathrm{C} 40 \mathrm{CV} 60 \mathrm{PCM} 40 \mathrm{~F}$.

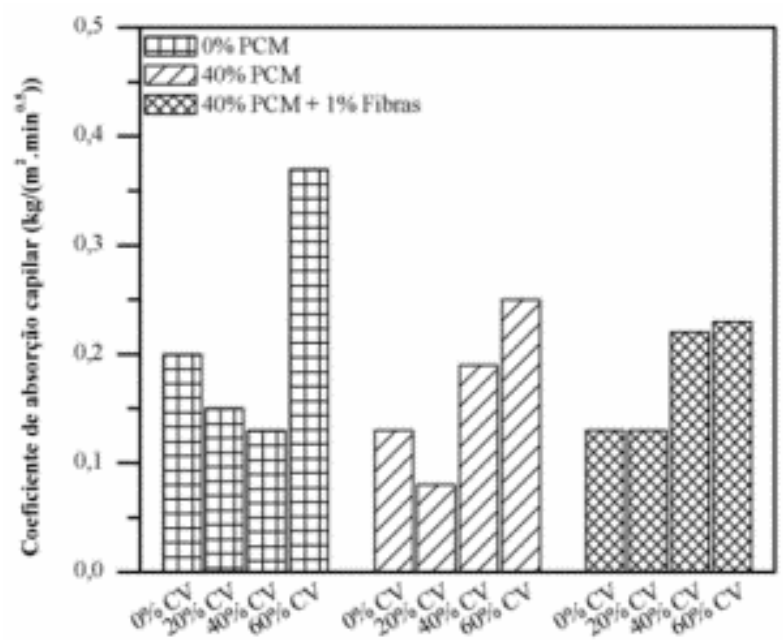

Figura 8: Coeficiente de absorção capilar das argamassas.

\subsection{Comportamento à flexão e compressão}

De acordo com os ensaios realizados foi possível observar uma diminuição na resistência à flexão e compressão originada pela introdução de cinzas volantes (Figura 11). Esta situação pode ser explicada pela mais baixa reatividade de cinzas volantes quando comparada com a reatividade do cimento [24-26]. No que respeita à resistência à flexão, a incorporação de $20 \%$ de cinzas volantes resultou numa diminuição do seu valor superior a $25 \%$. Em relação à resistência à compressão, a incorporação de $20 \%$ de cinzas volantes levou a uma diminuição superior a $30 \%$ comparativamente com as argamassas de referência. 

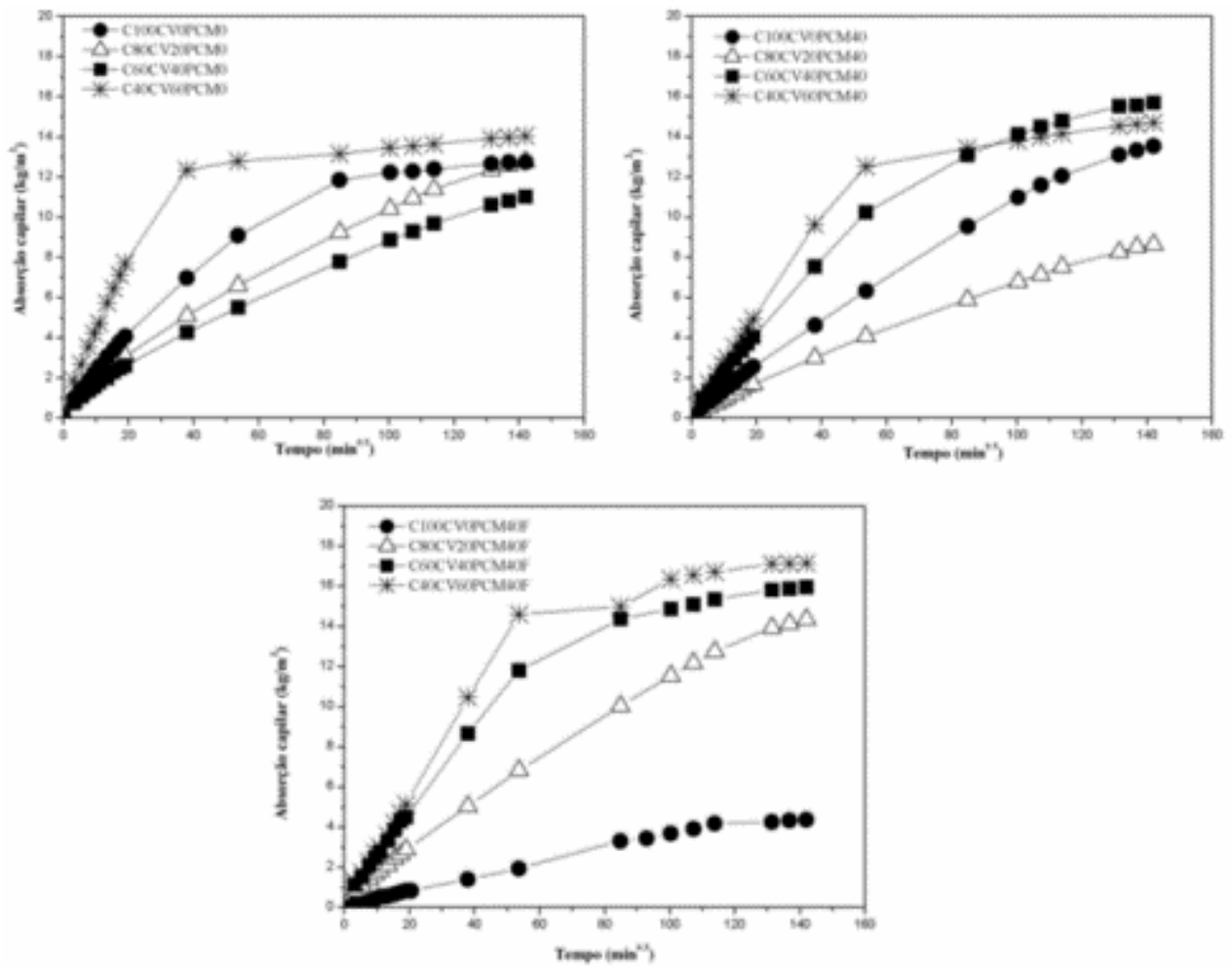

Figura 9: Absorção de água por capilaridade das argamassas.

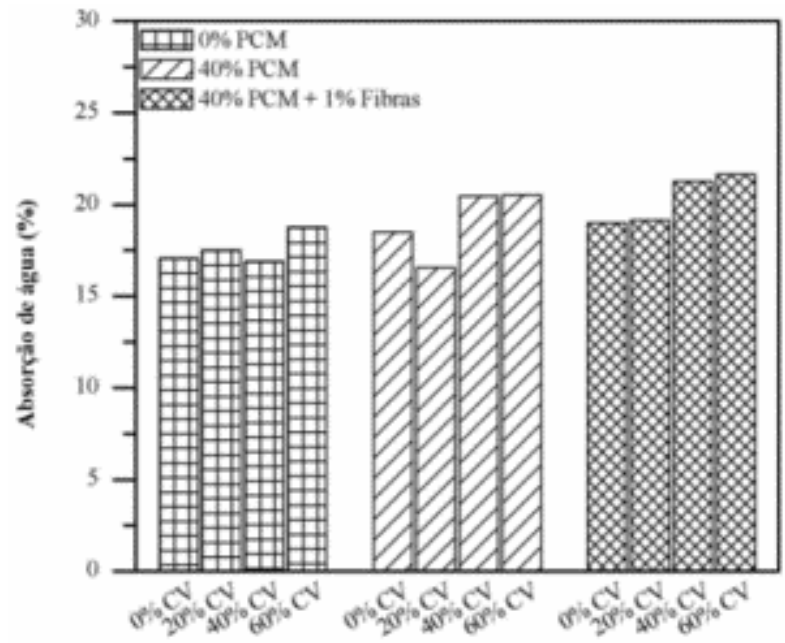

Figura 10: Absorção de água por imersão das argamassas.

Por outro lado, foi ainda possivel veriicar que a incorporação de $40 \%$ de microcápsulas de PCM provoca uma diminuição na resistência à flexão e compressão. Este comportamento é justificado pelo aumento da razão água/cimento devido à introdução de um teor mais elevado de PCM. A necessidade de uma maior quantidade de água nas argamassas com a incorporação de PCM encontra-se relacionada com a reduzida dimensão das partículas de PCM, originando uma maior microporosidade nas argamassas. No que diz respeito à diminuição da resistência à flexão, é importante notar que a aderência entre as microcápsulas de PCM e a matriz de cimento é inferior comparativamente com a ligação entre as partículas de areia e a matriz da argamassa. Por outro lado, as microcápsulas de PCM possuem uma menor resistência em comparação com as partículas de areia. Assim, a substituição das partículas de areia por um material com uma menor resistência (PCM) afeta negativamente a resistência à compressão.

A incorporação de fibras de poliamida em argamassas de cimento com incorporação de PCM e cinzas volantes conduz a uma ligeira diminuição na resistência à flexão e compressão, cerca de $10 \%$. Esta situação pode ser explicada pelo ligeiro aumento verificado na quantidade de água presente nas argamassas com in- 
corporação de fibras.
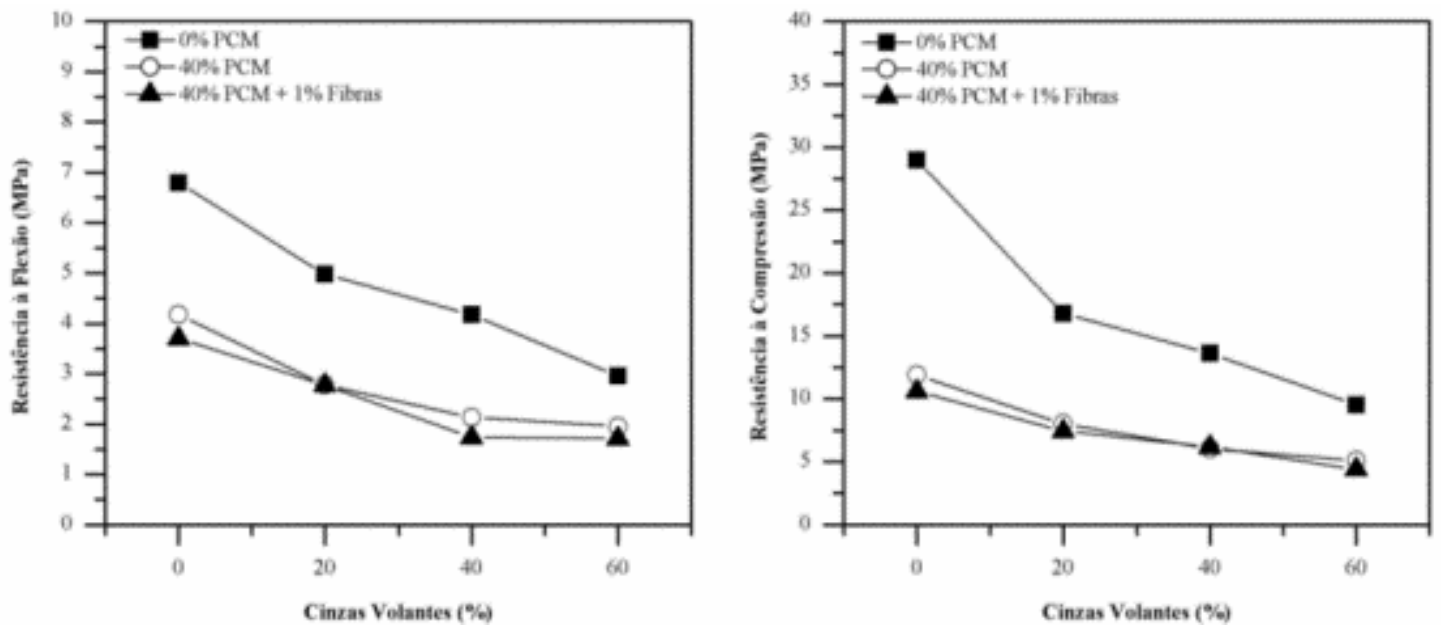

Figura 11: Resistência à flexão e compressão das argamassas.

\subsection{Aderência}

Os ensaios de aderência apenas foram realizados para as composições sem incorporação de microcápsulas de PCM e para as argamassas com a incorporação de PCM e fibras de poliamida, uma vez que as composições apenas com incorporação de PCM mostraram um elevado nível de fissuras de retração na superfície, impossibilitando a realização dos ensaios.

De acordo com a Figura 12, verifica-se uma diminuição na aderência superior a 5\% causada pela introdução de $20 \%$ de cinzas volantes. Este comportamento justifica-se pela menor reatividade das cinzas volantes. Por outro lado, a incorporação de $40 \%$ de microcápsulas de PCM leva a uma diminuição da aderência de cerca de $83 \%$, devido à aderência inferior entre as microcápsulas de PCM e a matriz de cimento em comparação com a ligação entre a areia e a matriz da argamassa, o que se confirma pelo tipo de rotura ocorrido.

As argamassas de cimento sem incorporação de PCM apresentaram uma rotura coesiva no substrato, com exceção das argamassas com incorporação de $60 \%$ de cinzas volantes que apresentaram uma rotura coesiva na argamassa. Por outro lado, nas argamassas de cimento com incorporação de PCM e fibras observouse uma rotura coesiva na argamassa.

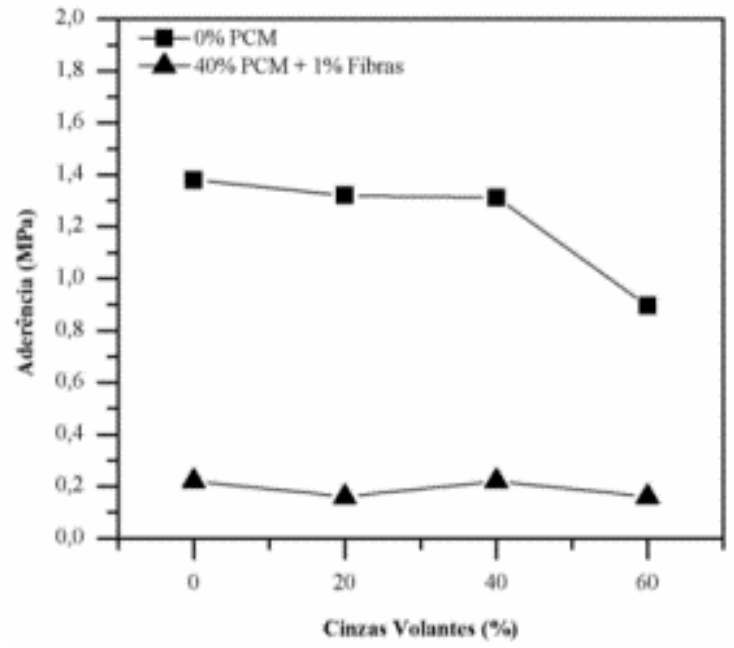

Figura 12: Aderência das argamassas.

\subsection{Comportamento térmico}

A Figura 13 apresenta o comportamento térmico das argamassas desenvolvidas durante a estação de verão. Foi possível observar que a célula revestida com a argamassa de referência ( $0 \%$ PCM) apresenta maiores 
temperaturas extremas, comparativamente com as células revestidas com argamassas aditivadas com PCM. Assim, foi possível verificar o efeito benéfico da incorporação do material de mudança de fase e da incorporação simultânea de PCM e cinzas volantes. Sendo que, o comportamento térmico das células com incorporação de PCM revela temperaturas internas mais estáveis e por um período de tempo mais longo. Este comportamento traduz-se num menor tempo de operação de sistemas de aquecimento e/ou arrefecimento, que permite uma diminuição dos consumos energéticos nos edifícios e consequentemente uma maior poupança no orçamento das famílias e menores impactos para o ambiente, uma vez que o recurso a fontes de energias não renováveis é diminuído.

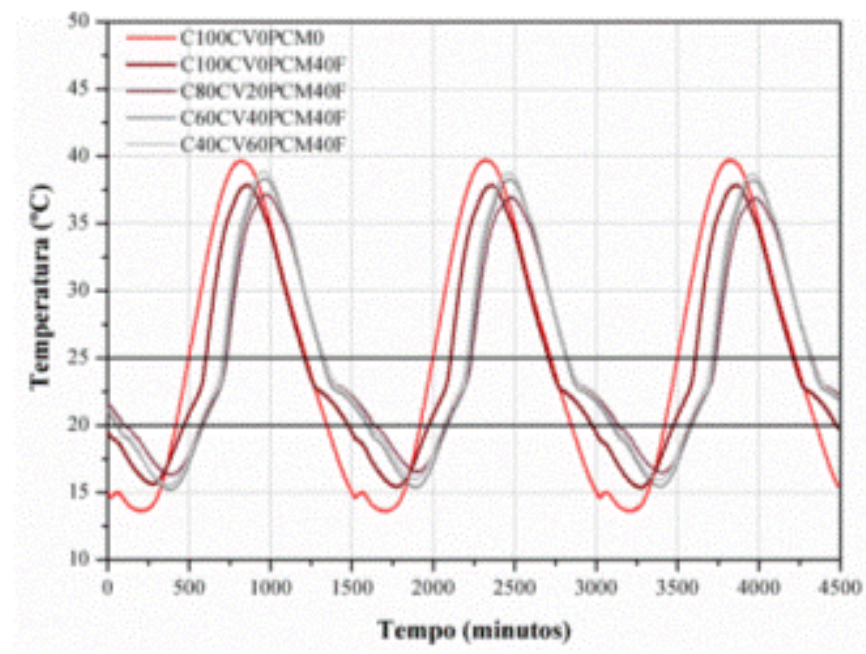

Figura 13: Comportamento térmico na estação de verão das argamassas com incorporação de cinzas volantes e microcápsulas de PCM.

A Figura 14 apresenta as temperaturas máximas e mínimas registadas no interior das células revestidas com as argamassas em análise. Sendo possível observar que a incorporação de $40 \%$ de PCM originou uma diminuição da temperatura máxima de cerca de 5\% na situação de arrefecimento e um aumento da temperatura mínima de cerca de $15 \%$ na situação de aquecimento. Por outro lado, a incorporação simultânea de PCM e cinzas volantes permite obter uma melhoria do desempenho térmico das argamassas. Sendo que a incorporação simultânea de $40 \%$ de PCM e $20 \%$ de cinzas volantes origina uma diminuição da temperatura máxima de cerca de $7 \%$ e um aumento da temperatura mínima de $20 \%$, comparativamente com a argamassa de referência. Contudo, maiores níveis de incorporação de cinzas volantes, mesmo permitindo a redução das temperaturas extremas, não se revelam tão interessantes comparativamente a uma incorporação de $20 \%$ de cinzas volantes. Assim, o melhor desempenho térmico das argamassas com incorporação de PCM e $20 \%$ de cinzas volantes encontra-se relacionado com o aumento da microporosidade, evidenciado pela maior quantidade de microporos com menores dimensões (Figura 7) e pelo aumento da absorção de água por capilaridade (Figura 8) e imersão (Figura 10).

A realização destes ensaios permitiu ainda a observação do desfasamento temporal das temperaturas extremas (Tabela 2). Tendo sido possível observar que a incorporação de PCM e cinzas volantes permite um aumento do desfasamento temporal, comparativamente com a argamassa de referência (C100CV0PCM). A argamassa com incorporação de PCM e $20 \%$ de cinzas volantes foi a que apresentou uma maior influência no desfasamento temporal na situação de aquecimento. A argamassa com incorporação de PCM e 40\% de cinzas volantes exibiu um maior desfasamento temporal na situação de arrefecimento. Ė de notar que existem sistemas de taxação da energia elétrica diferenciados em função da hora do dia, assim o desfasamento das temperaturas extremas e consequentes consumos elevados para fora das horas de maior procura, conduzem a uma clara vantagem económica.

A Tabela 3 apresenta as necessidades de aquecimento e arrefecimento associadas à utilização das diferentes argamassas. Verificou-se que a incorporação de PCM causou uma diminuição das necessidades de arrefecimento e aquecimento de $14 \%$ e $13 \%$, respetivamente. A incorporação de $20 \%$ de cinzas volantes causou uma diminuição de $2 \%$ e $10 \%$ nas necessidades de arrefecimento e aquecimento, respetivamente. Observou-se também que a argamassa de cimento com incorporação de $40 \%$ de PCM e $20 \%$ de cinzas volantes apresentou o melhor desempenho térmico, mostrando a maior diminuição nas necessidades de arrefecimento e aquecimento, em cerca de $18 \%$ e $23 \%$, respetivamente. 

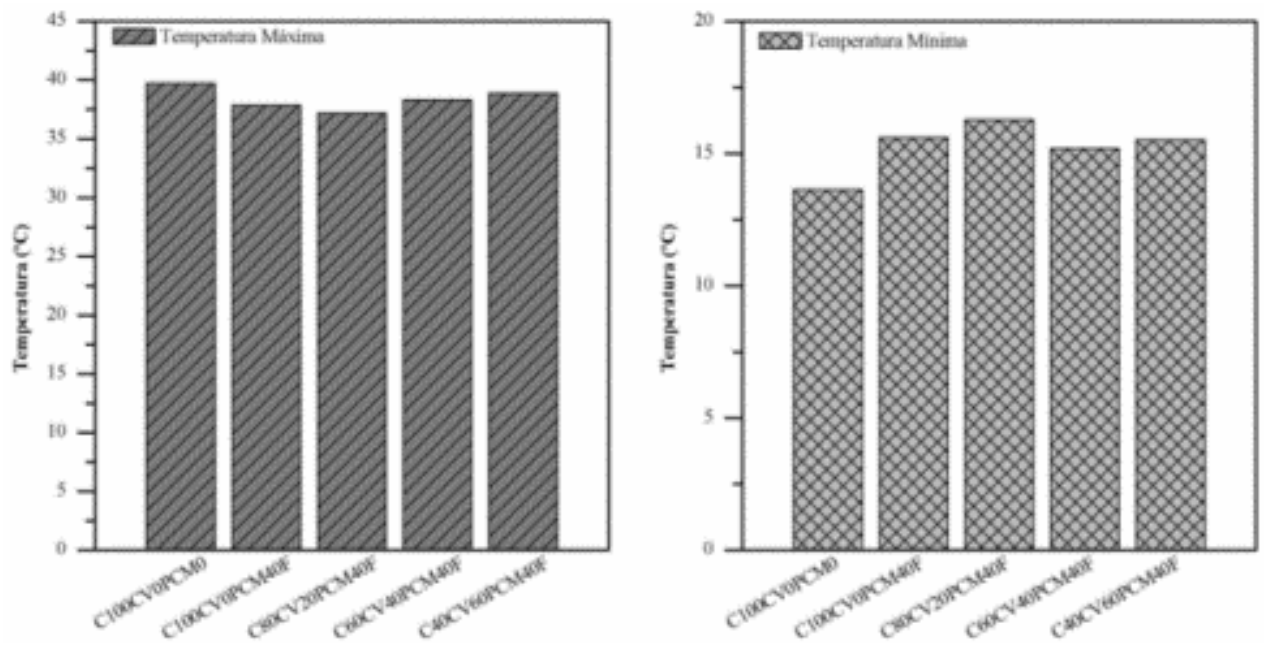

Figura 14: Temperatura máxima e mínima das células revestidas com argamassas com incorporação de cinzas volantes e microcápsulas de PCM - verão.

Tabela 2: Desfasamento temporal das temperaturas máximas e mínimas durante a estação de verão.

\begin{tabular}{l|l|l}
\hline \multirow{2}{*}{ COMPOSIÇÃO } & \multicolumn{2}{|l}{ DESFASAMENTO TEMPORAL (MINUTOS) } \\
\cline { 2 - 3 } & TEMPERATURA MÁXIMA & TEMPERATURA MÍNIMA \\
\hline C100CV0PCM0 & 0 & 0 \\
\hline C100CV0PCM40F & 71 & 72 \\
\hline C80CV20PCM40F & 73 & 104 \\
\hline C60CV40PCM40F & 78 & 62 \\
\hline C40CV60PCM40F & 60 & 93 \\
\hline
\end{tabular}

Tabela 3: Necessidades de climatização durante a estação de verão $\left(\mathrm{J} / \mathrm{m}^{3}\right)$.

\begin{tabular}{l|l|l|l}
\hline COMPOSIÇÃO & $\begin{array}{l}\text { NECESSIDADES DE } \\
\text { AQUECIMENTO }\end{array}$ & $\begin{array}{l}\text { NECESSIDADES DE AR- } \\
\text { REFECIMENTO }\end{array}$ & $\begin{array}{l}\text { NECESSIDADES DE } \\
\text { CLIMATIZAÇÃo }\end{array}$ \\
\hline C100CV0PCM0 & 253598 & 269623 & 523221 \\
\hline C100CV0PCM40F & 218974 & 226290 & 445264 \\
\hline C80CV20PCM40F & 196425 & 222218 & 418643 \\
\hline C60CV40PCM40F & 220047 & 221362 & 441409 \\
\hline C40CV60PCM40F & 200200 & 231667 & 431867 \\
\hline
\end{tabular}

Com base nos ensaios de caracterização do comportamento térmico, foi possível observar que, numa situação de verão as argamassas que apresentam um melhor desempenho são as argamassas com incorporação simultânea de $40 \%$ de PCM e $20 \%$ de cinzas volantes, uma vez que apresentam uma maior redução da temperatura máxima, um maior incremento na temperatura mínima, um maior desfasamento temporal e menores necessidades de climatização.

Em relação à estação da primavera (Figura15) mais uma vez, verificou-se um efeito benéfico na regulação da temperatura, melhorando o comportamento térmico com a incorporação simultânea de PCM e cinzas volantes nas argamassas. Nesta estação, observou-se ainda a inexistência de temperaturas superiores a $25^{\circ} \mathrm{C}$ para todas as argamassas com incorporação de PCM e com incorporação de PCM e cinzas volantes.

Observou-se também uma diminuição da temperatura máxima com a incorporação de PCM em cerca de $14 \%$ e um aumento da temperatura mínima em cerca de $11 \%$. A incorporação de cinzas volantes destacou esse comportamento, uma vez que a argamassa com incorporação de $40 \%$ de PCM e $20 \%$ de cinzas volantes (C80CV20PCM40F) apresentou uma diminuição da temperatura máxima de $15 \%$ e um aumento na temperatura mínima de $16 \%$ (Figura 16). Esse comportamento pode ser causado pelo aumento da microporosidade (Figura 7). 
A Tabela 4 apresenta o desfasamento temporal verificado na estação de primavera, na qual é possível observar um atraso superior a 243 minutos na situação de arrefecimento. Relativamente à situação de aquecimento o desfasamento temporal verificado foi menor, devido à menor influência da incorporação do PCM. No entanto, verificou-se que as composições com incorporação simultânea de PCM e cinzas volantes apresentaram o melhor desempenho.

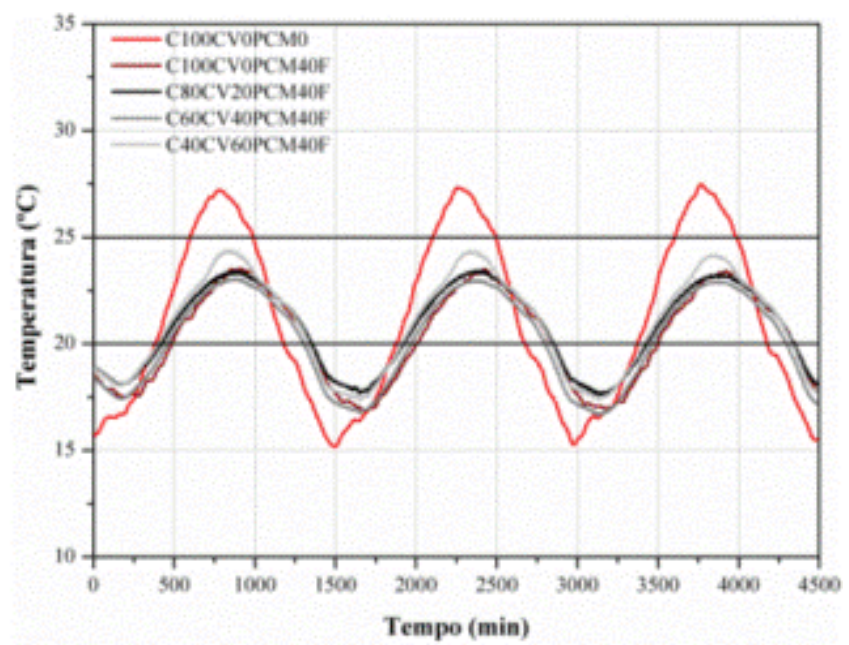

Figura 15: Comportamento térmico na estação de primavera das argamassas com incorporação de cinzas volantes e microcápsulas de PCM.
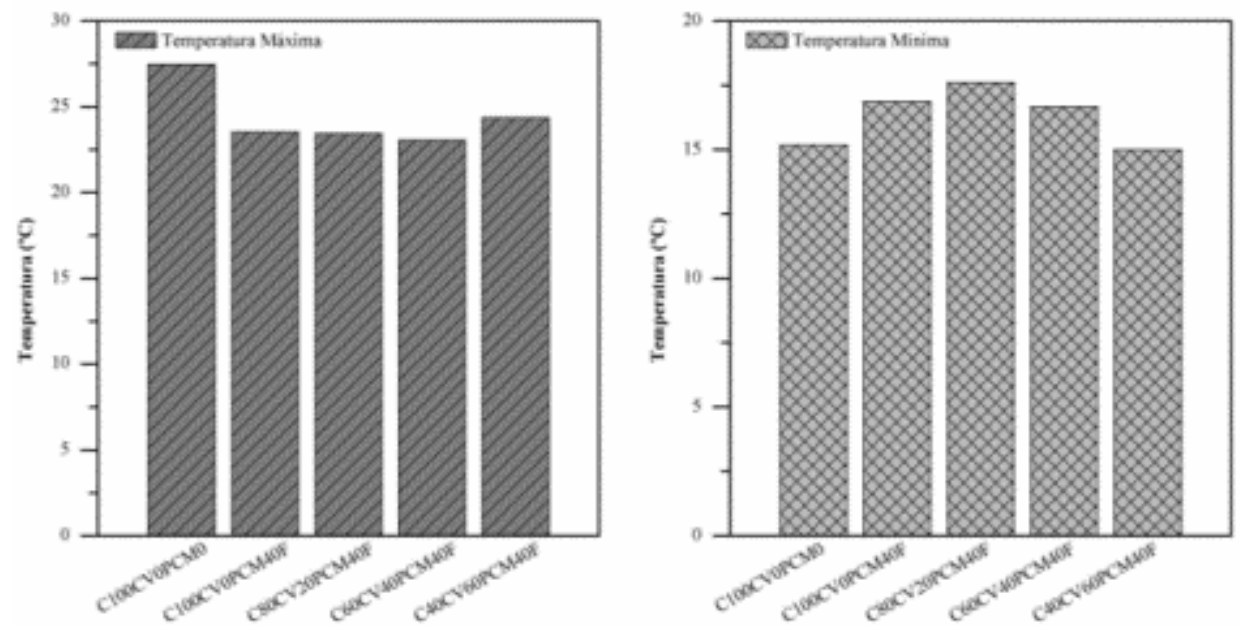

Figura 16: Temperatura máxima e mínima das células revestidas com argamassas com incorporação de cinzas volantes e microcápsulas de PCM - primavera.

Tabela 4: Desfasamento temporal das temperaturas máximas e mínimas durante a estação de primavera.

\begin{tabular}{l|l|l}
\hline \multirow{2}{*}{ COMPOSIÇÃo } & DESFASAMENTO TEMPORAL (MINUTOS) \\
\cline { 2 - 3 } & TEMPERATURA MÁXIMA & TEMPERATURA MÍNIMA \\
\hline C100CV0PCM0 & 0 & 0 \\
\hline C100CV0PCM40F & 243 & 20 \\
\hline C80CV20PCM40F & 264 & 15 \\
\hline C60CV40PCM40F & 253 & 35 \\
\hline C40CV60PCM40F & 271 & 0 \\
\hline
\end{tabular}


Relativamente às necessidades de aquecimento e arrefecimento verificou-se a eliminação das necessidades de arrefecimento para esta estação do ano, para todas as argamassas com incorporação de PCM e com incorporação de PCM e cinzas volantes. No que diz respeito às necessidades de aquecimento observou-se uma diminuição superior a 5\% com a incorporação de PCM. No entanto, as argamassas com incorporação simultânea de PCM e cinzas volantes apresentaram queda de $14 \%$ nas necessidades de aquecimento em relação às argamassas com incorporação de PCM. Observou-se também que a argamassa com incorporação de 40\% de PCM e $20 \%$ de cinzas volantes apresenta o melhor desempenho, mostrando a maior diminuição das necessidades de aquecimento, cerca de $18 \%$ e uma eliminação das necessidades de arrefecimento (Tabela 5).

Tabela 5: Necessidades de climatização durante a estação de primavera $\left(\mathrm{J} / \mathrm{m}^{3}\right)$.

\begin{tabular}{l|l|l|l}
\hline COMPOSIÇÃO & $\begin{array}{l}\text { NECESSIDADES DE } \\
\text { AQUECIMENTO }\end{array}$ & $\begin{array}{l}\text { NECESSIDADES DE AR- } \\
\text { REFECIMENTO }\end{array}$ & $\begin{array}{l}\text { NECESSIDADES DE } \\
\text { CLIMATIZAÇÃo }\end{array}$ \\
\hline C100CV0PCM0 & 255083 & 263041 & 518124 \\
\hline C100CV0PCM40F & 241884 & 0 & 241884 \\
\hline C80CV20PCM40F & 209154 & 0 & 209154 \\
\hline C60CV40PCM40F & 243546 & 0 & 243546 \\
\hline C40CV60PCM40F & 210294 & 0 & 210294 \\
\hline
\end{tabular}

A Figura 17 apresenta o comportamento térmico na estação do outono. Verificou-se a eliminação de temperaturas inferiores a $20^{\circ} \mathrm{C}$ para as argamassas com incorporação de microcápsulas de PCM. Foi possível observar também que as temperaturas máximas não sofreram variações significativas e um aumento na temperatura mínima superior a $10 \%$ (Figura 18).

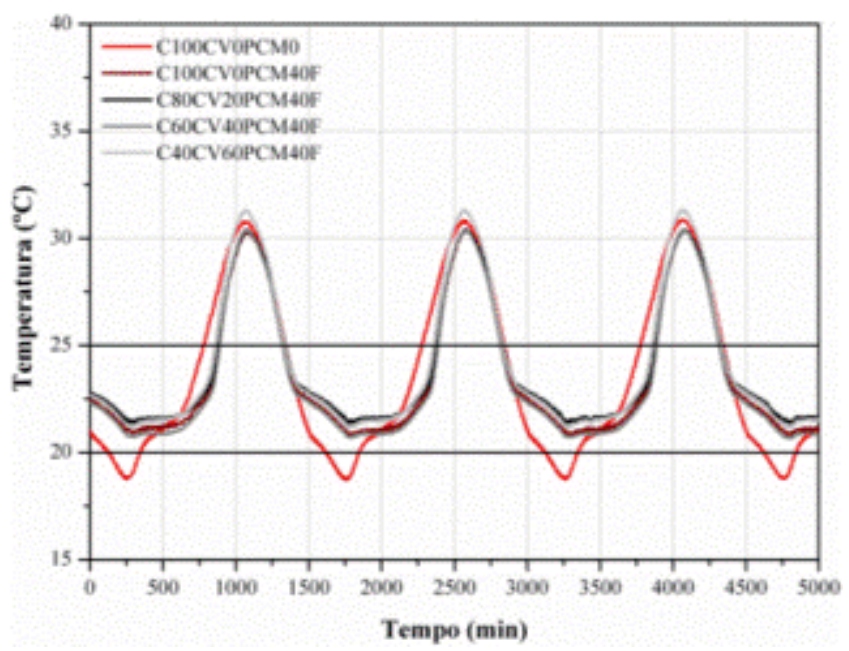

Figura 17: Comportamento térmico na estação de outono das argamassas com incorporação de cinzas volantes e microcápsulas de PCM.

A Tabela 6 apresenta o desfasamento temporal das temperaturas extremas. Sendo que, foi possível observar um desfasamento superior a 64 minutos e a 287 minutos nas situações de arrefecimento e aquecimento, respetivamente. Mais uma vez, a composição com incorporação de $40 \%$ de PCM e $40 \%$ de cinzas volantes apresenta o melhor comportamento.

Em relação às necessidades de climatização, verificou-se uma diminuição das necessidades de arrefecimento superior a $15 \%$ e a eliminação das necessidades de aquecimento (Tabela 7). Nesta estação, as argamassas com incorporação de 40\% de PCM e 40\% de cinzas volantes (C60CV40PCM40F) exibem o melhor comportamento reduzindo em $23 \%$ as necessidades de arrefecimento. 

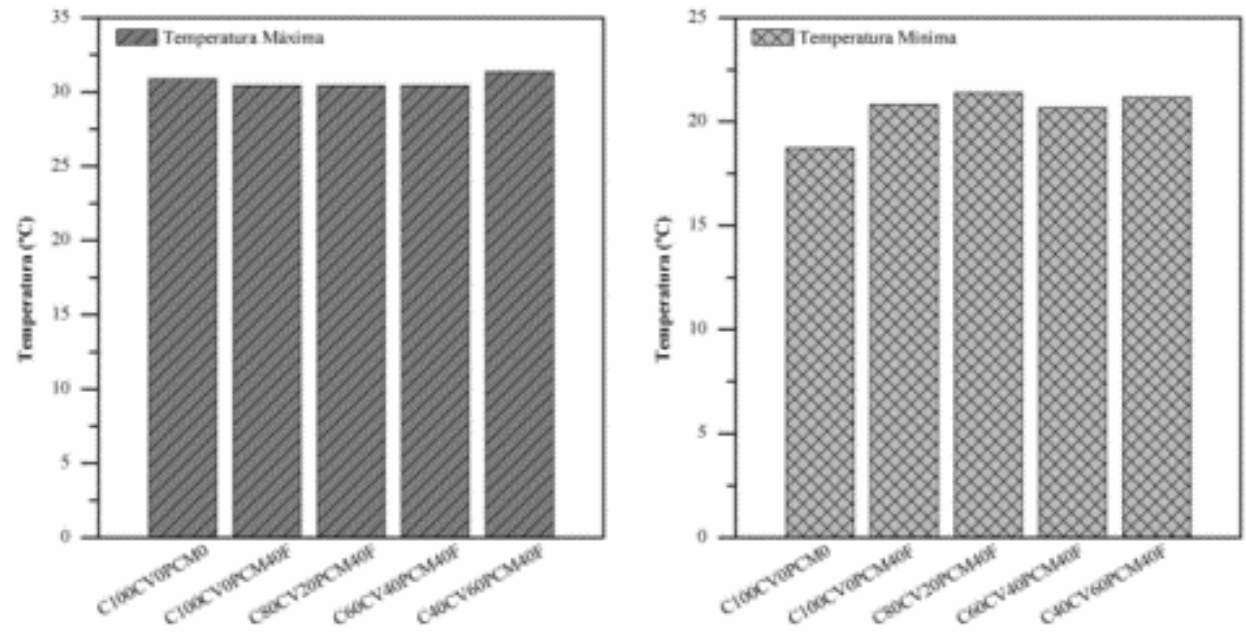

Figura 18: Temperatura máxima e mínima das células revestidas com argamassas com incorporação de cinzas volantes e microcápsulas de PCM - outono.

Tabela 6: Desfasamento temporal das temperaturas máximas e mínimas durante a estação de outono.

\begin{tabular}{l|l|l}
\hline \multirow{2}{*}{ COMPOSIÇÃo } & \multicolumn{2}{|l}{ DESFASAMENTO TEMPORAL (MINUTOS) } \\
\cline { 2 - 3 } & TEMPERATURA MÁXIMA & TEMPERATURA MÍNIMA \\
\hline C100CV0PCM0 & 0 & 0 \\
\hline C100CV0PCM40F & 67 & 328 \\
\hline C80CV20PCM40F & 67 & 315 \\
\hline C60CV40PCM40F & 95 & 321 \\
\hline C40CV60PCM40F & 64 & 287 \\
\hline
\end{tabular}

Tabela 7: Necessidades de climatização durante a estação de outono $\left(\mathrm{J} / \mathrm{m}^{3}\right)$.

\begin{tabular}{l|l|l|l}
\hline COMPOSIÇÃO & $\begin{array}{l}\text { NECESSIDADES DE } \\
\text { AQUECIMENTO }\end{array}$ & $\begin{array}{l}\text { NECESSIDADES DE AR- } \\
\text { REFECIMENTO }\end{array}$ & $\begin{array}{l}\text { NECESSIDADES DE } \\
\text { CLIMATIZAÇÃo }\end{array}$ \\
\hline C100CV0PCM0 & 256836 & 265013 & 521849 \\
\hline C100CV0PCM40F & 0 & 211723 & 211723 \\
\hline C80CV20PCM40F & 0 & 215439 & 215439 \\
\hline C60CV40PCM40F & 0 & 203255 & 203255 \\
\hline C40CV60PCM40F & 0 & 225531 & 225531 \\
\hline
\end{tabular}

De acordo com os resultados dos ensaios térmicos, pode observar-se que a incorporação simultânea de cinzas volantes e microcápsulas de PCM melhora o comportamento térmico das argamassas desenvolvidas. Esta situação pode ser justificada pelo aumento da microporosidade das argamassas com adição de cinzas volantes, evidenciado pela maior quantidade de microporos com dimensões reduzidas e maiores níveis de absorção de água.

A avaliação das argamassas na estação de inverno não foi possível, um vez que a lei de temperatura utilizada e representativa da região norte de Portugal, não atinge o ponto de fusão do PCM. Assim, seria necessário utilizar um equipamento de aquecimento para aumentar as temperaturas dentro das células de teste de pequena escala até ao ponto de fusão PCM. No entanto, neste estudo o objetivo principal foi testar o comportamento térmico sem qualquer adição de equipamentos de climatização.

\section{CONCLUSÕES}

Esta investigação avaliou o comportamento mecânico, físico e térmico das argamassas de cimento com incorporação simultânea de microcápsulas de PCM e cinzas volantes. Verificou-se a possibilidade de incorporação simultânea de resíduos industriais e materiais de mudança de fase em argamassas para revestimento 
interior. Por outro lado, a adição destes materiais originou alterações significativas nas propriedades das argamassas no estado fresco e endurecido.

Os resultados obtidos mostram que a incorporação de PCM em argamassas origina um aumento do teor de água, com o objetivo de obter uma trabalhabilidade adequada, devido às reduzidas dimensões das microcápsulas de PCM. Por outro lado, a incorporação de $20 \%$ de cinzas volantes originou uma diminuição do teor de água, uma vez que as partículas de cinzas volantes possuem uma forma mais próxima da esférica quando comparadas às partículas de cimento.

As observações microscópicas mostraram uma boa interação entre todos os constituintes das argamassas de cimento, evidenciado pela ausência de fissuras e pela presença de partículas de cimento hidratadas ligadas às microcápsulas de PCM. Por outro lado, a ausência de material aglomerado mostra que o processo de mistura utilizado foi apropriado.

Relativamente às propriedades mecânicas, observou-se uma diminuição da resistência à flexão, compressão e aderência com a incorporação simultânea de PCM e cinzas volantes. Este fenómeno é uma consequência da menor reatividade das partículas de cinzas volantes quando comparadas com as partículas de cimento. Por outro lado, o maior teor de água origina um aumento da microporosidade das argamassas.

No que confere ao comportamento térmico, a utilização de argamassas de cimento com incorporação de microcápsulas de PCM, provou ser uma estratégia eficiente para a obtenção de uma construção com elevado valor de sustentabilidade, devido à redução das temperaturas máximas e mínimas e também pelo aumento do desfasamento temporal das temperaturas extremas. A incorporação de cinzas volantes que substituem parte do cimento resultou em um aumento da eficiência energética das argamassas incorporando PCM. Assim, a incorporação simultânea de PCM e cinzas volantes leva a uma diminuição no consumo de energia, redução no consumo e exploração de combustíveis fósseis e impactos ambientais negativos associados à utilização de sistemas de aquecimento e arrefecimento. A incorporação de um resíduo industrial ainda permite uma melhoria ambiental, uma vez que reduz a quantidade de materiais depositados em aterros sanitários e reduz a extração de matérias-primas.

Pode-se observar que a argamassa com incorporação de $20 \%$ de cinzas volantes e $40 \%$ de microcápsulas PCM (C80CV20PCM40F) apresentou melhor desempenho térmico, com comportamento mecânico compatível com a aplicação como argamassa interior em edifícios. Assim, pode-se concluir que foi possível obter argamassas com incorporação de PCM e cinzas volantes com comportamento térmico melhorado. No entanto, a incorporação de cinzas volantes não deve exceder $20 \%$ da substituição do cimento.

\section{AGRADECIMENTOS}

Os autores desejam expressar os seus agradecimentos à Fundação para a Ciência e Tecnologia (FCT) pelo financiamento deste trabalho no âmbito do projeto UID/ECI/04047/2013-UM.

\section{BIBLIOGRAFIA}

[1] BEHERA, M., BHATTACHARYYA, S. K., MINOCHA, A. K., et al., "Recycled aggregate from C\&D waste \& its use in concrete - A breakthrough towards sustainability in construction sector: A review", Construction and Building Materials, v.68, pp. 501-516, Oct. 2014.

[2] BILGEN, S., "Structure and environmental impact of global energy consumption", Renewable and Sustainable Energy Reviews, v. 38, pp. 890-902, Oct. 2014.

[3] PAMPURI, L., CEREGHETTI, N., STREPPARAVA, D., et al., "Analysis of the electricity consumptions: A first step to develop a district cooling system", Sustainable Cities Society, v. 23, pp. 23-36, May. 2016.

[4] SILVA, S., ANDRADE, J., "Investigation of mechanical properties and carbonation of concretes with construction and demolition waste and fly ash", Construction and Building Materials, v. 153, pp. 704-715, Oct. 2017.

[5] BAGHERIA, A., ZANGANEH, H., ALIZADEH, H., et al., "Comparing the performance of fine fly ash and silica fume in enhancing the properties of concretes containing fly ash", Construction and Building Materials, v.47, pp. 1402-1408, Oct. 2013.

[6] LAI, C., CHEN, R.H., LIN, C., "Heat transfer and thermal storage behaviour of gypsum boards incorporating micro-encapsulated PCM", Energy and Buildings, v. 42, pp. 1259-1266, Aug. 2010. 
[7] ENTROP, A., BROUWERS, H., REINDERS, A., "Experimental research on the use of microencapsulated Phase Change Materials to store solar energy in concrete floors and to save energy in Dutch houses", Solar Energy, v. 85, pp. 1007-1020, May. 2011.

[8] CUNHA, S., AGUIAR, J., FERREIRA, V., TADEU, A., "Influence of Adding Encapsulated Phase Change Materials in Aerial Lime based Mortars", Advanced Materials Research, v. 687, pp. 255-261, 2013.

[9] CUNHA, S., AGUIAR, J., FERREIRA, V., et al., "Mortars based in different binders with incorporation of phase change materials: Physical and mechanical properties", European Journal of Environmental Civil Engineering, v. 19, pp. 1216-1233, 2015.

[10] AHMAD, M., BONTEMPS, A., SALLÉE, H., et al., "Thermal Testing and Numerical Simulation of a Prototype Cell Using Light Wallboards Coupling Vacuum Isolation Panels and Phase Change Material”, Energy and Buildings, v. 38, pp. 673-681, Jun. 2006.

[11] CUNHA, S., AGUIAR, J., FERREIRA, V., et al., "Mortars with phase change materials - Part I: Physical and mechanical characterization”, Key Engineering Materials, v. 634, pp. 22-32, 2015.

[12] CUNHA, S., AGUIAR, J., FERREIRA, V., et al., "Influence of the type of phase change materials microcapsules on the properties of lime-gypsum thermal mortars", Advanced Engineering Materials, v. 16, pp. 433-441, 2014.

[13] CUNHA, S., AGUIAR, J., KHERADMEND, M., et al., "Thermal mortars with incorporation of PCM microcapsules", Restoration of Buildings and Monuments, v. 19, pp. 171-177, 2012.

[14] CUNHA, S., AGUIAR, J., FERREIRA, V., et al., "Influence of Adding Encapsulated Phase Change Materials in Aerial Lime based Mortars", Advanced Materials Research, v. 687, pp. 255-261, 2013.

[15] CUNHA, S., AGUIAR, J., PACHECO-TORGAL, F., "Effect of temperature on mortars with incorporation of phase change materials", Construction and Building Materials, v. 98, pp. 89-101, Nov. 2015.

[16] CUNHA, S., AGUIAR, J., FERREIRA, V., et al., "Mortars Based in different binders with incorporation of phase change materials: Physical and mechanical properties", European Journal of Environmental and Civil Engineering, v. 19, pp. 1216-1233, 2015.

[17] EUROPEAN COMMITTEE FOR STANDARDIZATION (CEN), EN 1015-3, "Methods of test for mortar for masonry - Part 3: Determination of consistence of fresh mortar (by flow table)", 1999.

[18] EUROPEAN COMMITTEE FOR STANDARDIZATION (CEN), EN 1015-18, "Methods of test for masonry - Part 18: Determination of water absorption coefficient due to capillary action of hardened mortar", 2002.

[19] LABORATÓRIO NACIONAL DE ENGENHARIA CIVIL (LNEC), Especificação E 394, "Betões Determinação da absorção de água por imersão", 1993.

[20] EUROPEAN COMMITTEE FOR STANDARDIZATION (CEN), EN 1015-11, "Methods of test for masonry - Part 11: Determination of flexural and compressive strength of hardened mortar", 1999.

[21] EUROPEAN COMMITTEE FOR STANDARDIZATION (CEN), EN 1015-12, "Methods of test for mortar for masonry - Part 12: Determination of adhesive strength of hardened rendering and plastering mortars on substrates", 2000.

[22] CAMÕES, A., ROCHA, P., JALALI, S., et al., "High-Performance Concrete Using Fly Ash", Third Internacional Conference of High-Performance Concrete, pp. 15-32, 2002.

[23] CHINDAPRASIRT, P., HOMWUTTIWONG, S., SIRIVIVATNANON, V., "Influence of fly ash fineness on strength, drying shrinkage and sulfate resistance of blended cement mortar", Cement and Concrete Research, v. 34, pp. 1087-1092, 2004.

[24] XU, B., LI, Z., "Performance of novel thermal energy storage engineered cementitious composites incorporating a paraffin/diatomite composite phase change material", Applied Energy, v. 121, pp. 114-122, 2014.

[25] HUANG, X., RANADE, R., ZHANG, Q., et al., "Mechanical and thermal properties of green lightweight engineered cementitious composites", Construction and Building Materials, v. 48, pp. 954-960, 2013.

[26] HUANG, X., RANADE, R., ZHANG, Q., et al., "Development of green engineered cementitious composites using iron ore tailing as aggregates”, Construction and Building Materials, v. 44, pp. 757-764, 2013. 


\section{ORCID}

Sandra Cunha

https://orcid.org/0000-0002-6384-1355

José Aguiar

https://orcid.org/0000-0003-3954-5721

Victor Ferreira

https://orcid.org/0000-0002-6295-1333

António Tadeu

https://orcid.org/0000-0003-2535-8458 